\section{Entre protocolos e sujeitos: qualidade do cuidado hospitalar em um serviço de hematologia}

\author{
Between protocols and subject: quality of \\ hospital care in a hematology service
}

\section{Entre protocolos e individuos: calidad del cuidado hospitalario en un servicio de hematología}

\section{Resumo}

No artigo, apresentamos parte dos resultados do estudo desenvolvido no Hospital Edgar Santos, da Universidade Federal da Bahia (HUPES), que analisou a experiência de melhoria da qualidade da assistência em um contexto de acreditação hospitalar. $O$ artigo volta-se para o serviço de hematologia e tem seu foco na qualidade do cuidado e processos intersubjetivos. A investigação foi pautada na perspectiva qualitativa, empregando-se entrevistas e observação. Do ponto de vista teórico, os trabalhos de Campos, Cecílio e Merhy reconhecem a natureza complexa do cuidado em saúde, sua dimensão micropolitica e intersubjetiva, e a capacidade dos profissionais de produção de sentidos e de criatividade. Para compreender os processos de articulação psicossocial e de mobilização subjetiva dos profissionais empregamos conceitos da psicossociologia francesa de Enriquez e da psicodinâmica do trabalho de Dejours. A análise foi organizada em três eixos: articulação psicossocial e o imaginário de autogestão; vínculo e afeto: singularização do cuidado e clínica do sujeito; trabalho real e equipe de saúde. Destacamos como uma das principais conclusões a constituição de um imaginário de autogestão, expresso no compartilhamento de projetos, expectativas e algumas formas de interpretar $e$ operar a realidade, que têm por base representações, afetivamente investidas, de autonomia e unidade. Ao lado de elementos técnicos, como protocolos, é realçado o julgamento profissional, próprio à dimensão intersubjetiva, permitindo a singularização do cuidado. Compreendemos que na cena assistencial o trabalho real é atravessado por ajustes que demonstram a cooperação entre os profissionais.

Qualidade da Assistência à Saúde; Administração dos Cuidados ao Paciente; Equipe de Assistência ao Paciente

\author{
Creuza da Silva Azevedo 1 \\ Lilian Miranda 1 \\ Marilene de Castilho Sá 1 \\ Victor Grabois 1 \\ Gustavo Matta 1 \\ Marcela Cunha 1
}

doi: 10.1590/0102-331X00043817

\author{
Correspondência \\ C. S. Azevedo \\ Escola Nacional de Saúde Pública Sergio Arouca, Fundação \\ Oswaldo Cruz. \\ Rua Leopoldo Bulhões 1480, sala 716, Rio de Janeiro, RJ \\ 21041-210. Brasil. \\ creuza@ensp.fiocruz.br \\ ${ }^{1}$ Escola Nacional de Saúde Pública Sergio Arouca, Fundação
Oswaldo Cruz, Rio de Janeiro, Brasil.
}




\section{Introdução}

Nas últimas duas décadas, têm se intensificado os debates voltados para a gestão e qualidade do cuidado nos hospitais, destacando-se iniciativas de acreditação e segurança do paciente ${ }^{1}$ como estratégias de humanização da assistência. Nesse contexto, considerando-se a natureza complexa e multidimensional do cuidado em saúde, vêm sendo desenvolvidas abordagens que destacam a dimensão micropolítica e intersubjetiva das organizações, reconhecendo-se o papel central dos processos dialógicos e intersubjetivos na gestão e produção do cuidado 2,3,4.

Envolvidos nessa discussão, apresentamos parte dos resultados de um estudo desenvolvido no Hospital Edgar Santos, da Universidade Federal da Bahia (HUPES), que analisou a experiência de produção do cuidado e de implementação de mudanças nos processos de trabalho e de melhoria da qualidade da assistência hospitalar. Trata-se de um recorte da pesquisa Avaliação de Experiências Inovadoras no Âmbito da Organização e Gestão da Atenção em Hospitais do SUS, que deu origem a um banco de 239 hospitais do SUS, com 100 ou mais leitos, resultante de um inquérito eletrônico sobre experiências de qualificação da gestão e organização do cuidado 5,6. Essas experiências foram analisadas, entre outras variáveis, quanto à sua abrangência, bem como as abordagens, estratégias e dispositivos de organização do cuidado adotados. No resultado geral do inquérito, destacaram-se os processos de contratualização, acreditação e certificação ${ }^{5}$. Uma segunda etapa da pesquisa previu ainda uma investigação qualitativa em profundidade, por meio da realização de três estudos de caso, destinados à análise da singularidade dos processos organizacionais e dos desafios enfrentados na gestão e produção do cuidado 6. O HUPES foi selecionado para um dos casos, considerando-se sua natureza jurídica e localização geográfica, em associação às variáveis anteriormente apontadas.

No presente artigo, apresentamos uma parte da pesquisa que foi desenvolvida num setor específico, a hematologia, selecionado para uma investigação em profundidade por se tratar de um dos três serviços em que foi implantado o modelo de equipe de gestão, uma das inovações gerenciais do hospital. Nosso objetivo é analisar uma experiência de coordenação e produção do cuidado, considerando, principalmente, sua dimensão intersubjetiva e psicossocial.

No HUPES, a busca pela melhoria da qualidade do cuidado foi estruturada, principalmente, baseando-se em um processo de Acreditação. Essa constitui uma estratégia de avaliação externa com o objetivo de melhoria da qualidade, utilizando padrões de qualidade pré-determinados. Ainda recente no Brasil, a avaliação proposta pela Acreditação é baseada no grau de conformidade da organização aos padrões de qualidade pré-estabelecidos ${ }^{7}$.

Neste artigo, a acreditação é tratada apenas como cenário de processos de mudança organizacional, já que nosso foco é a qualidade do cuidado e suas relações com os processos intersubjetivos. Esses compreendem a capacidade de mobilização subjetiva dos trabalhadores, constituída pelos afetos despertados pelo trabalho em cada profissional e pelas ligações (ou vínculos) que estes estabelecem entre si, com os usuários e com a instituição. Tais ligações configuram a base do funcionamento dos sujeitos no grupo e permeiam os processos de cooperação e articulação intersubjetiva.

A mobilização subjetiva do trabalhador diz respeito a uma vivência subjetiva em que recursos psicológicos do profissional e de outros membros do coletivo de discussões sobre o trabalho são mobilizados para uma operação simbólica de construção de sentido para o trabalho. A utilização desses recursos está vinculada à dinâmica contribuição-retribuição simbólica, que pressupõe o reconhecimento do trabalhador pelos seus pares e pela hierarquia. Com base nessas experiências o sujeito amplia a sua capacidade de sentir, pensar e inventar para a realização do trabalho 8 .

Tal compreensão aponta para o delicado processo de coordenação do cuidado no hospital, sendo centrais a autonomia dos trabalhadores e sua capacidade irredutível de produção de sentidos e de criatividade 2,3,9,10,11. Buscando identificar os principais pontos de contato ou interseção entre os vários autores brasileiros que tratam teoricamente dessas questões e, no caso de alguns, vêm desenvolvendo novas experiências na gestão dos serviços de saúde e na organização e qualificação da assistência, destacamos: (i) o foco na análise dos aspectos cotidianos e processuais dos serviços de saúde; (ii) o tensionamento ou questionamento dos limites do paradigma biomédico para a compreensão dos processos saúde/doença e intervenção sobre os mesmos; (iii) a preocupação com a integralidade do cuidado e uma concepção "alargada" ou "ampliada" do cuidado e das ações necessárias para pro- 
duzi-lo; (iv) a preocupação com a centralidade dos sujeitos e dos processos intersubjetivos, tanto na produção do cuidado como no modo de se fazer a gestão.

Entre as principais abordagens, destacam-se, sobretudo, os trabalhos de Gastão Wagner de Souza Campos, Emerson Elias Merhy e Luiz Carlos de Oliveira Cecílio que fundaram um pensamento próprio em planejamento e gestão em saúde, na defesa de um modelo de gestão estratégica apoiado fundamentalmente na gestão colegiada em todos os níveis dos serviços de saúde, valendo-se do conceito de "cogestão" 11. Discutindo o delicado processo de coordenação do cuidado no hospital, os autores apresentam as principais características de sua proposta de reorganização da gestão hospitalar, tendo como referência a produção do cuidado, na perspectiva da integralidade e, consequentemente, a definição de "linhas de cuidado" com as respectivas gerências 12 .

Com preocupações análogas, Campos 13 vem defendendo uma reformulação e ampliação da clínica, que inclui a problemática do sujeito/produção de subjetividade como consequência de sua visão sobre o trabalho em saúde e do trabalho gerencial. Considerando a realidade hospitalar ${ }^{11}$, propõe a reconstituição de um "traço artesanal" ao trabalho clínico, sua singularização, de modo a diminuir a fragmentação do trabalho que, em geral, produz a desresponsabilização do profissional pelo seu objeto de cuidado. $\mathrm{O}$ traço artesanal envolve a possibilidade de o profissional acompanhar todo o processo de cuidado do usuário, ainda que não seja o executor de todas as intervenções. Envolve, ainda, o reconhecimento das necessidades, condições e potencialidades de cada caso, bem como de cada trabalhador e equipe que o acompanhará. O traço artesanal implica também o reconhecimento dos limites à padronização e à prescrição, caracterizando o trabalho criativo sobre singularidades.

$\mathrm{Na}$ esteira dessas ideias, compreendemos que, embora as evidências científicas sejam a base para constituição de diretrizes clínicas e, portanto, para a definição de protocolos, o processo de julgamento envolvido em cada caso, com uma história clínica e social singular, aponta desafios para os processos de decisão clínica. Estão presentes nesse contexto não apenas elementos racionais, mas também elementos simbólicos e intersubjetivos - entre profissionais e pacientes - pelas possibilidades, de cada profissional, de aproximação da visão de mundo do paciente e de seus familiares, de se sensibilizar com o sofrimento do outro e de reconhecer sua própria implicação no processo de definição da terapêutica.

Estabelecendo um diálogo com os autores antes mencionados, empregamos o referencial da psicossociologia francesa 14,15,16 e alguns conceitos da abordagem da psicodinâmica do trabalho ${ }^{8,17}$. A psicossociologia se apoia em uma perspectiva psicanalítica para compreender a organização e seus processos de mudança como uma realidade viva, na qual os sujeitos vivem seus desejos de afiliação. Dessa forma, esta abordagem recusa-se a separar o indivíduo e o coletivo, o afetivo e o institucional, procurando, assim, examinar os processos de articulação psicossocial.

Para tanto, a abordagem psicossociológica adotada 14 compreende os processos psíquicos na sua articulação às experiências de pertencimento e constituição de laços sociais, expressando possibilidades de investimento afetivo no trabalho e na organização. Com essas preocupações, ressaltamos a dimensão simbólica e imaginária que embasa subjetivamente o vínculo com o trabalho, os processos intersubjetivos e grupais e suas implicações para a cooperação e solidariedade. Destacamos, particularmente, a categoria de imaginário organizacional considerada por Enriquez 15,16 como um sistema de interpretação afetivamente investido, voltado para a construção de sentido, equivalente a um imaginário social comum que representa "aquilo que somos, aquilo que queremos vir a ser ... e em que tipo de organização desejamos intervir ou existir" 16 (p. 57).

Para tratar a dimensão psicossocial do trabalho em saúde, apoiamo-nos também na obra de Cristopher Dejours ${ }^{8}$, que destaca o papel do trabalhador e sua contribuição aos ajustes do trabalho, por meio do zelo e da engenhosidade. $O$ autor emprega a categoria de real do trabalho que corresponde "ao que se deixa conhecer por quem trabalha por sua resistência ao saber-fazer, aos procedimentos, às prescrições, aquilo que se revela, geralmente, como forma de resistência à habilidade técnica, ao conhecimento" 17 (p. 38). Para ele, a experiência do real "é quando todo o meu saber se choca contra a resistência do mundo" 17 (p. 39). Trabalhar, então, é compreendido pelo autor como recomeçar e, sobretudo, encontrar uma solução possível, destacando então as possibilidades do trabalhador descobrir, criar e inovar modos de atuar na organização do trabalho baseando-se nas interpretações que faz do que está prescrito, mas também das experimentações sobre o trabalho. Esse é o trabalho real 17. Aqui é importante destacar a resso- 
nância entre o plano do sujeito e o coletivo e, assim, as articulações psicossociais ${ }^{18}$. Ressaltamos então que o trabalho real, ou seja, aquele que efetivamente é produzido, é "tanto subjetivo como intersubjetivo e repousa nas energias do domínio afetivo" 8 (p. 134). Para Dejours 17 , o trabalhador em sua experiência adquire não apenas novas habilidades, mas também amplia a sua sensibilidade, conhecendo seus limites e podendo identificar novas qualidades e virtuosismos e, assim, obter prazer.

\title{
Metodologia
}

\section{Cenário do estudo}

O HUPES é referência na alta complexidade no SUS da Bahia para um grande número de especialidades médicas. Contava, no momento da pesquisa, com 278 leitos ativos. Inserido num processo de mudança organizacional, materializada em inúmeras políticas e ações, o hospital buscou a melhoria da articulação com a Secretaria Estadual de Saúde da Bahia, no sentido de inserir-se mais no SUS, atendendo às demandas da capital e do interior.

Em 2009, o hospital iniciou o processo de acreditação. Um conjunto de melhorias foi desenvolvido, tendo a experiência de acreditação alavancado o processo gerencial. Um novo regimento e organograma foram desenvolvidos constituindo-se um Conselho Gestor. No âmbito da gestão do cuidado, a proposta foi criar Equipes de Gestão com um coordenador médico e um de enfermagem, implantadas até o momento da pesquisa na UTI, na Unidade Coronariana, na Unidade Metabólica e na Hematologia.

\section{O processo de investigação}

O estudo desenvolvido no HUPES, do qual este artigo é um recorte, envolveu o processo de mudança organizacional orientado pelo processo de Acreditação, que foi realizado por meio de visitas e imersão no campo por três pesquisadores, no período de outubro a novembro de 2012. Para explorar as iniciativas inovadoras, procuramos, em uma primeira fase, associar reuniões com a direção do hospital a visitas e análise de um conjunto de documentos institucionais.

As estratégias de pesquisa fundamentais no HUPES foram a realização de entrevistas com gestores e profissionais (40) e observações de atividades, tais como visitas multidisciplinares, rounds e reuniões de equipe. Desse modo, procuramos explorar a pluralidade de caminhos de melhoria da qualidade que vinham sendo desenvolvidos. Nesse processo, selecionamos a Hematologia como campo de estudo qualitativo mais aprofundado, pois se trata de um serviço que passou por um período de inovação gerencial, além de reestruturação física e ampliação de perfil assistencial.

O processo de análise teve como base a imersão e leitura flutuante das transcrições das entrevistas e registros das observações participantes, considerando-se, especialmente, os sentidos e representações, produzidos pelos trabalhadores e gestores, relativos ao seu trabalho, à equipe e ao serviço. Dessa forma, três eixos de análise resultaram do trabalho de ausculta do material empírico e confronto com a literatura: articulação psicossocial e o imaginário de autogestão; vínculo e afeto: singularização do cuidado e clínica do sujeito; trabalho real e equipe de saúde.

O trabalho foi aprovado pelo Comitê de Ética em Pesquisa da Escola Nacional de Saúde Pública Sergio Arouca/Fundação Oswaldo Cruz (ENSP/Fiocruz) em 5 de maio de 2010, protocolo no 68/10, CAAE: 0071.0.031.000-1.

\section{Resultados e discussão}

\begin{abstract}
A hematologia
O serviço de hematologia está organizado como uma linha de cuidados integrando atividades de ambulatório, quimioterapia e internação e transplante de medula óssea. Esse último procedimento
\end{abstract}


tornou-se possível a partir de 2010, quando começou um projeto - Projeto de transplante de medula óssea - em parceria com a Secretaria Estadual de Saúde da Bahia, viabilizando a realização de obras físicas, aquisição de equipamentos e contratação de pessoal para o serviço.

A constituição de uma enfermaria específica para a hematologia e a outra para o transplante de medula óssea é recente. Essa configuração foi inaugurada em 2010, quando o serviço passou a dispor de 15 leitos de hematologia e 5 para o transplante de medula óssea, sendo esta a única unidade no estado a oferecer tratamento integral para pacientes que necessitam deste tipo de tratamento. A relevância assistencial do serviço é ainda maior tendo em vista as limitações da rede de saúde pública na Bahia: "...somos o único Hospital Público de Hematologia do estado" (médico).

O fato de tal reconfiguração advir de um projeto com financiamento e monitoramento próprios, em parceria com a Secretaria Estadual de Saúde, permitiu que o serviço se caracterizasse como uma "unidade gerencial". Trata-se de unidade clínica e administrativa, responsável pelo acompanhamento de uma série de procedimentos gerenciais (informações e prestação de contas, acompanhamento da produção) que depois se desdobraram no âmbito da contratualização do HUPES com a Secretaria Municipal de Saúde. Assim, a estrutura da hematologia representa uma inovação gerencial do HUPES na busca de maior autonomia e responsabilidade. Para tanto, trabalha-se com uma equipe constituída pela coordenação de hematologia, coordenador da transplante de medula óssea, chefia administrativa, coordenação de enfermagem do ambulatório e de enfermaria voltada para articulação de assistência, ensino e pesquisa. A possibilidade de monitoramento é uma das funções da unidade gerencial bastante realçada: "...a nossa produção, quimio, internamento, transplante, o que a gente produz. A gente sabe quem são os funcionários. O gerenciamento do recursos humanos interno nós temos isso bem dimensionado, apesar de tudo estar vinculado ao hospital, mas algum nivel de gerenciamento nós temos" (médico).

O serviço é híbrido do ponto de vista dos contratos de pessoal, contando com profissionais vinculados à Universidade Federal da Bahia, FAPEX (Fundação de Apoio do Hospital) ou cedidos de outras instituições, tendo, portanto, cargas horárias distintas. Por meio dessa realidade, viabilizou-se que a equipe de enfermagem, dado seu caráter altamente especializado, tenha sido selecionada no âmbito do projeto, tornando-se exclusiva da hematologia.

Segundo os entrevistados, os profissionais, em geral, acabam trabalhando mais tempo do que aquele previsto por sua carga horária contratual, pois estão envolvidos numa intensa rotina de reuniões e também desenvolvem a função de ensino. Trata-se de dedicação e empenho que expressam o grande investimento no trabalho. Outra especificidade da hematologia diz respeito ao funcionamento de uma lógica matricial na gestão da equipe, de tal modo que os enfermeiros, farmacêuticos e demais profissionais são coordenados internamente pelo serviço, embora respondam formalmente, por exemplo, à direção de enfermagem e coordenação de farmácia do HUPES.

\section{Articulação psicossocial: o imaginário de autogestão}

O modo como a hematologia organizou seus processos de trabalho e gestão, associado às oportunidades geradas pelo Projeto de transplante de medula óssea, favoreceu a articulação psicossocial, que analisamos por meio da noção de Imaginário de Autogestão. Como vimos anteriormente, para Enriquez 15,16, o imaginário se constitui a partir em um conjunto de representações afetivamente construídas e investidas numa realidade, de tal modo que os profissionais compartilham projetos, expectativas e algumas formas de interpretar e operar esta realidade. No caso da hematologia, observamos que os profissionais parecem compartilhar da certeza de que compõem uma unidade que se distingue por sua autonomia nos processos de gestão, tida como de maior alcance para a assistência. Tal compartilhamento, embora não precise ser explicitado nas discussões, influencia fortemente no modo como os sujeitos se envolvem com o trabalho:

"Isso já é um exemplo da nossa vontade de ser essa unidade gerencial. Então eu acho que os funcionários se sentem parte de um único grupo, com todas as dificuldades que é trabalhar com pessoas, não é?" (médico).

Consideramos, assim, que predomina na hematologia o entendimento de que o serviço pode se gerir com relativa autonomia em relação ao hospital como um todo (por exemplo, cria rotinas, protocolos e impressos próprios, além de contar com arranjos contratuais de trabalho diferenciados). Trata-se de uma valorização da autonomia na gestão do processo de trabalho que é fortalecida pela 
própria característica do hospital que, sendo universitário, propicia experiências mais independentes, na medida em que parte de seus profissionais estão também ligados à universidade, desenvolvem pesquisas no serviço e contam com certa legitimidade para propor rotinas assistenciais.

O imaginário é construído com base no compartilhamento de uma história, permeada por experiências singulares, como o projeto de transplante de medula óssea, mas também por certas rotinas que, no caso da hematologia, propiciam encontros regulares e trocas de informações, experiências e afetos. Contudo, é interessante notar que tais rotinas são uma espécie de matéria prima e ao mesmo tempo de efeito do imaginário. Observamos, por exemplo, o fortalecimento da equipe multidisciplinar no serviço, operacionalizado por meio de uma sistemática semanal de reuniões, nas quais se discutem temas assistenciais, casos clínicos, resultados de congressos, definição de protocolos de quimioterapia, elaboração de impressos e questões administrativas.

O processo coletivo de debate mostra-se, portanto, como suporte para uma perspectiva mais integrada da gestão que, associada à lógica de unidade gerencial e à história de parceria do hospital com a Secretaria Estadual de Saúde da Bahia, conforma um contexto favorável à constituição de vínculos de pertencimento dos profissionais ao serviço, configurando o imaginário de autogestão.

Sob esse imaginário, além dos debates coletivos, observam-se outros elementos que compõem a articulação psicossocial com base na qual é possível realizar um trabalho julgado pela equipe como de qualidade. Um deles diz respeito ao suporte propiciado por alguns profissionais com funções e formações específicas. Analisando o processo de trabalho, os entrevistados apontam a presença essencial dos médicos diaristas que fundamentam a tomada de decisão clínica. Citam também o round diário, que inclui duas atividades centrais: elaboração do plano terapêutico e avaliação de riscos do paciente. Casos que envolvem tomadas de decisões drásticas como, por exemplo, passar o paciente para cuidados paliativos são levados para a reunião com toda a equipe: ambulatório e enfermaria. " $E$ a gente estabeleceu que nenhuma decisão desse porte vai ser tomada com menos de três médicos (...). Isso protege o indivíduo e melhora a qualidade..." (médico).

As discussões coletivas de casos apoiam a atividade assistencial e de ensino, mas também desempenham uma função grupal de amparo simbólico ${ }^{14}$ para os profissionais, especialmente nas decisões que têm alta repercussão para o tratamento e vida de pacientes graves. $O$ parecer do médico que acompanha o paciente diariamente, bem como o compartilhamento de decisões, parecem significar processos que asseguram à equipe sua autonomia na condução do caso e sua capacidade de deliberar corretamente. Compreendemos, ainda, que tais encontros funcionam para o grupo também como fonte de identificação com a proposta do serviço e reconhecimento da contribuição de cada profissional. Sob o imaginário da autogestão, os profissionais sentem-se pertencentes a um grupo que pode e sabe conduzir seu trabalho de modo autônomo.

Vale ressaltar que os entrevistados reconhecem não apenas elementos técnicos, mas também subjetivos e dialógicos nos processos de interpretação e julgamento profissionais. Tal postura favorece, simultaneamente, a expressão da singularidade da experiência dos profissionais e a troca de visões como componentes igualmente fundamentais na decisão clínica. $\mathrm{Na}$ cena assistencial, por vezes o real do trabalho, como considerou Dejours 8, é atravessado por ajustes e acordos que demonstram a cooperação entre os profissionais especializados, mas também a presença de elementos intersubjetivos que, por vezes, se expressam de maneira difusa por uma intuição e mesmo pela escuta do desejo do paciente.

"Mas geralmente nós três [médicos do staff] fazemos as visitas para então na quarta-feira - que a gente tem que decidir com mais profissionais. Porque às vezes nem todas as respostas estão nos livros, não é? E é o bom senso e a experiência de cada um" (médica).

Os ajustes no real do trabalho envolvem a interpretação e o uso que os profissionais fazem das rotinas padronizadas e normas estabelecidas no cotidiano assistencial. A equipe da hematologia considera que tais rotinas são fundamentais para a oferta de um cuidado qualificado e resolutivo, tendo recebido de modo bastante positivo a proposta da Acreditação pela qual passava o hospital. Mas, é importante lembrar que o serviço introduziu procedimentos operacionais padrão antes da Acreditação, aperfeiçoando-os neste processo, especialmente aqueles relativos à segurança do paciente. Segundo Gouvêa \& Travassos 19, a segurança é uma importante dimensão da qualidade que se refere ao direito das pessoas de terem reduzido ao mínimo aceitável o risco de um dano desnecessário associado com o cuidado de saúde aceitável. A definição de segurança do paciente do Canadian Patient 
Safety Dictionary, fornecida por Quinto Neto 20, contempla a ideia de redução e mitigação de atos não seguros dentro do sistema de assistência à saúde associada à utilização de boas práticas para alcançar resultados ótimos para o paciente.

Quanto aos impressos introduzidos pela Acreditação, a enfermagem mostra adesão, embora perceba dificuldade de preenchimento por outros profissionais. Há uma avaliação positiva do processo de melhoria contínua e de acreditação: "...eu acho que na busca de identificação do paciente, segurança, fluxos clínicos, a gente está muito bom. Não é perfeito” (médico).

Chamou-nos atenção que a Acreditação parece compreendida, por alguns profissionais, como equivalente ao uso de protocolos clínico-assistenciais na busca da melhoria da qualidade:

"Nós temos que ter protocolos, nós temos que ter uma busca para a excelência, temos que ter perfis, para que o paciente chegue aqui, todo paciente que seja um paciente difuso de grandes células $b$, tenha o mesmo padrão de atendimento (...) o mesmo tipo de registro, o mesmo tipo de linha de raciocínio, da busca da segurança do paciente" (médica).

É interessante notar que a mesma médica que valoriza, no trecho anterior, o julgamento pela experiência, que reconhece a escolha e o limite de cada paciente, também referenda a busca de padronização e de protocolos clínicos apontando que tais caminhos, na prática, estão articulados. Para além dos protocolos e processos ligados à acreditação, os profissionais valorizam os fluxos assistenciais e consideram que o processo de melhoria contínua está avançando.

Ganhou destaque também a revisão multidisciplinar dos protocolos de quimioterapia, como exemplo de cuidado com a qualidade: "...nós ficamos dois anos revisando com uma equipe multidisciplinar, com a enfermeira, com a farmacêutica e com o médico, todos os protocolos de quimio" (médico). E quanto à segurança do paciente foi enfatizada a rotina do serviço própria à oncologia: “...quando a gente prescreve uma quimioterapia, o médico prescreve, o farmacêutico assina e o enfermeiro assina. Quimioterápico a gente considera de alto risco. Você não pode errar uma dose" (médico).

Nota-se que o processo de incorporação e valorização das propostas da acreditação na hematologia aconteceu com base em uma construção coletiva que foi pautada por protocolos e rotinas anteriormente criados pelo próprio serviço. Novamente nos deparamos com elementos que sugerem um funcionamento pautado na autogestão, na medida em que o serviço adota as novas orientações do hospital, mas o faz de modo assumidamente singular. Tal singularização, a nosso ver, configurase como um dos determinantes da oferta de um cuidado também singular, conforme passaremos a discutir.

\section{Vínculo e afeto: singularização do cuidado e clínica do sujeito}

Em diferentes entrevistas foi destacada a natureza interativa e afetiva do trabalho e do vínculo com o paciente oncológico, a delicadeza e as dificuldades que envolvem o tratamento dos pacientes oncológicos, como uma dimensão da qualidade do cuidado.

"Principalmente para os pacientes que estão graves, a notícia de um momento difícil, ela precisa ser dada, ela precisa ser compartilhada. Até porque o paciente tem o direito de escolher até quando ele quer ir" (médico).

Emerge nas entrevistas a natureza intersubjetiva própria ao contexto de cuidado, sendo enfatizado como elemento central a responsabilidade por estabelecer uma relação de confiança entre profissionais e pacientes:

"Então, na hora que eu me entrego aos cuidados da pessoa, é uma relação de fé, não é? É uma relação de confiança (...). É uma parceria, que a gente institui no início e que ela não pode ser quebrada. Porque na hora que a gente tem que dar notícias desfavoráveis, também o paciente precisa estar resguardado e confiante de que aquela notícia dada é em cima de um tratamento que foi feito o melhor possível" (médica).

A gravidade dos casos e a responsabilidade marcam a atuação dos profissionais que, no estudo realizado, parecem mostrar-se sensíveis ao sofrimento do outro. Questões próprias à precariedade imposta pelo adoecimento levam a equipe ao contato com questão da fragilidade humana e da finitude de forma intensa, trazendo exigências de elaboração psíquica.

"Não é fácil encarar a morte e ninguém quer morrer. Nós também às vezes sofremos. A gente se apega, a gente não quer que o paciente morra. Não é?” (médica).

A gravidade dos casos demanda uma articulação da dimensão biomédica aos aspectos sociais e intersubjetivos. É o que observamos no transplante de medula óssea, procedimento de alta complexi- 
dade e com resultado duvidoso que, para Pereira 21 (p. 68), implica um trânsito entre "uma perda confirmada e um ganho incerto", já que se chega à decisão deste procedimento como a última linha possível de tratamento curativo adotado após tentativas com outros tratamentos sem obter a resposta esperada.

A reunião semanal de transplante de medula óssea, nas palavras de um dos profissionais, "É onde a gente discute os pacientes. Vê a lista e faz as programações de mobilização, transplante, discute os pacientes que já transplantaram, os que vão ser admitidos" (enfermeira). Ela pareceu funcionar como espaço de enfrentamento da complexidade biomédica, social e emocional da decisão do transplante, conformando-se como espaço de deliberação coletiva do setor, como um arranjo da coordenação do cuidado que enfatiza o compartilhamento de responsabilidade entre profissionais.

Na reunião, argumentos objetivos, quantificáveis e técnicos se misturavam aos aspectos da qualidade de vida do paciente, assim como a questões singulares de cada paciente em seu sofrimento. $\mathrm{O}$ staff, por meio de relatos médicos, da psicologia, do serviço social e da farmácia, mostrou-se sensível à problemática dos pacientes como sujeitos com suas singularidades, destacando-se a capacidade de escuta e decisão partilhada.

Nesse contexto, surgiu a argumentação de uma médica quanto ao encaminhamento de um paciente para o transplante halogênico em São Paulo, Brasil, ainda que estivesse sendo considerado, como alternativa, o uso de outros quimioterápicos. O reconhecimento do desejo do paciente, de sua situação familiar e social, e o risco de vida envolvido, foram elementos centrais que pesaram na decisão do encaminhamento para o transplante.

Ainda que seja reconhecida a importância dos protocolos médicos para a qualidade dos processos assistenciais, os profissionais reforçam que os casos exigem muito para a tomada de decisões: " $O$ paciente decide até onde ir e a enfermagem e médicos devem estar atentos" (médica).

Assim, a especificidade e o contato com a fragilidade e a morte podem estar associados a um olhar mais sensível sobre o processo de cuidado e as decisões envolvidas 14 . Nesse caminho, compreendemos que há na hematologia uma concepção "alargada" e ampliada da clínica, capaz de adaptar condutas pautadas em padronização terapêutica e protocolos às necessidades advindas das particularidades do doente. Estaríamos perante uma ampliação de foco da clínica: pessoas concretas, com riscos e vulnerabilidades encarnadas e contextualizadas, o que implica uma clínica do sujeito 11,13 e não da doença. Podemos compreendê-la como um caminho que conjuga de forma intensa e entrelaçada as dimensões técnica e interativa/intersubjetiva do trabalho, que se expressam no trabalho em equipe.

\section{Trabalho real e equipe de saúde}

Voltados para a análise do trabalho em equipe e apoiados na abordagem da psicodinâmica do trabalho de Dejours, podemos inicialmente identificar no processo decisório sobre o transplante o emprego do que o autor denominou critérios de "validação cognitiva instrumental" 17 (p. 111), procurando de forma precisa mais eficiência e qualidade com base no conhecimento dos diversos profissionais.

Conforma-se então um espaço de deliberação coletiva, caminho para a explicitação e visibilidade da maneira de cada um trabalhar, tornando-a inteligível para os demais. São momentos de exposição do saber-fazer, da engenhosidade, mas também das infrações às regras que demandam confiança e lealdade entre os colegas e com o chefe 17 . Nesse processo, observam-se consensos, mas também controvérsias, que se tornam a base para o desenvolvimento do coletivo.

No entanto, sabe-se que a lacuna que sempre existe entre o trabalho prescrito e o trabalho real é submetida "a acordos entre os agentes no mundo social" 17 (p. 111), pautados também por elementos do mundo subjetivo de cada sujeito e da dinâmica do grupo. Assim, o sentido do trabalho é construído para os profissionais "a partir da implicação de cada um como sujeito na elaboração e no ajuste das regras que organizam a cooperação" 17 (p. 112).

As discussões de casos possibilitam, do ponto de vista da análise dos processos intersubjetivos, que a equipe habite um espaço intermediário "entre" a realidade objetiva das condições clínicas do paciente e a realidade subjetiva de cada profissional que experimentou diversificadas sensações durante o contato com ele. Nesse espaço, delimitado coletivamente com base em cada uma das exposições sobre o paciente, os profissionais se mantêm em contato com o caso, mas podem também se distanciar dele, o que permite percebê-lo de outras perspectivas. Ao mesmo tempo, podem reconhecer as diferentes 
formas que os colegas têm de sentir, avaliar e prognosticar, e neste trânsito entre presente, passado e futuro, criar projetos terapêuticos singulares 22 .

Destacarmos então que o trabalho vivo dos coletivos e a cooperação propriamente dita “...passa por uma mobilização específica e insubstituivel dos trabalhadores na concepção, no ajuste e na gestão da organização do trabalho" 17 (p. 103). Essa compreensão reafirma então que os profissionais não se colocam apenas como instrumentos de um conhecimento científico. Cuidar envolve um papel de intérprete dos recursos biomédicos, de busca de conhecimentos sistematizados, concomitantemente, a busca por responder a uma demanda de cada sujeito na sua experiência de adoecimento.

\section{Conclusões}

Considerando nosso principal objetivo neste artigo - compreender a experiência de coordenação e produção do cuidado com base, principalmente, na sua dimensão intersubjetiva e psicossocial - destacamos como uma das principais conclusões do estudo a constituição de um imaginário de autogestão, oriundo da história de representações (como, por exemplo, a ideia de autonomia, unidade e compartilhamento) afetivamente construídas e investidas pelo conjunto de profissionais e gestores do serviço analisado. Desse modo, podemos afirmar que tal imaginário é sustentado pela mobilização psíquica cotidiana dos profissionais, implicados e zelosos pela qualidade das práticas. Tal processo, favorece, portanto, a cooperação e construção de sentido para o trabalho realizado. Podemos considerar que esse imaginário é a base para um projeto comum, projeto grupal que supõe um espaço para a confiabilidade e criatividade. Assim, na perspectiva teórica com que estamos trabalhando, o processo de coordenação do cuidado e a construção de projetos coletivos podem ser compreendidos como fruto de um projeto técnico e especializado, mas também humano e intersubjetivo, que precisa ser não apenas intelectualmente pensado, mas também afetivamente sentido 15 .

No serviço analisado pudemos compreender que na cena assistencial o real do trabalho, como considerou Dejours 8, é atravessado por ajustes e acordos que demonstram, com diferentes nuances, a cooperação entre os profissionais especializados por meio de debate técnico permeado por elementos intersubjetivos. Nesses processos, destacam-se o papel do reconhecimento - como retribuição simbólica pelas contribuições de cada trabalhador à organização do trabalho, à sua mobilização subjetiva, ao seu investimento no trabalho, às responsabilidades e riscos que assume - e da possibilidade de transparência sobre o trabalho real, com os ajustes aportados por cada trabalhador, condição de instauração da confiança e da cooperação.

Embora estejam presentes nas unidades estudadas as práticas próprias à Acreditação, como o emprego de protocolos clínicos e impressos para a padronização de processos, ao mesmo tempo é realçado o papel de interpretação e julgamento profissional, considerando elementos técnicos, mas também subjetivos e dialógicos.

Em nossas reflexões destacamos a relevância dos encontros regulares das equipes para discutir casos e acordar linhas de intervenção, expressando então que as ações de saúde não se articulam apenas por intermédio de instrumentos normativos e racionais, tornando-se essencial explicitar as conexões entre as intervenções e reconhecer as diferenças entre os profissionais para que as ações possam levar à melhoria da qualidade do cuidado.

A experiência da hematologia do HUPES mostra que os hospitais podem se configurar como espaço heterogêneo, permitindo o desenvolvimento de experiências gerenciais e de cuidado inovadoras. 


\section{Colaboradores}

C. S. Azevedo e L. Miranda foram responsáveis pela concepção da pesquisa e redação do artigo. M. C. Sá foi responsável pela concepção da pesquisa, e revisão final do artigo. V. Grabois, M. Cunha e G. Matta foram responsáveis pela concepção da pesquisa, e participaram da coleta e análise das informações. Todos os autores aprovaram a versão final do artigo a ser publicada.

\section{Referências}

1. Portela MC, Martins M, Lopes CMB. Caderno de estudo: gestão da qualidade em saúde. In: Barbosa PR, Costa e Silva V, organizadores. Programa de gestão em saúde. Rio de Janeiro: Escola Nacional de Saúde Pública Sergio Arouca, Fundação Oswaldo Cruz; 2010. p. 114.

2. Merhy E. Em busca da qualidade dos serviços de saúde: os serviços de porta aberta para a saúde e o modelo tecno-assistencial em defesa da vida. In: Cecílio L, organizador. Inventando a mudança na saúde. São Paulo: Editora Hucitec; 1994. p. 117-60.

3. Merhy E. Em busca do tempo perdido: a micropolítica do trabalho vivo em saúde. In: Merhy E, Onocko R, organizadores. Agir em saúde: um desafio para o público. São Paulo: Editora Hucitec/Buenos Aires: Lugar Editorial; 1997. p. 71-112.

4. Mendes EV. Os grandes dilemas do SUS: tomos I e II. Salvador: Casa da Qualidade Editora; 2001.

5. Azevedo CS, Sá MC, Miranda L, Grabois V. Caminhos da organização e gestão do cuidado em saúde no ambito hospitalar brasileiro. Revista de Política, Planejamento e Gestão em Saúde 2010; 1:95-115.

6. Azevedo CS, Sá MC, Cunha M, Mata GC, Miranda L, Grabois V. Racionalização e construção de sentido na gestão do cuidado: uma experiência de mudança em um hospital do SUS. Ciênc Saúde Coletiva 2017; 22:1991-2002.

7. La Forgia GM, Couttolenc BF. Desempenho hospitalar no Brasil. Em busca da excelência. São Paulo: Editora Singular; 2009.

8. Dejours C. Da psicopatologia à psicodinâmica do trabalho. Rio de Janeiro: Editora Fiocruz/ Brasília: Paralelo 15; 2004.

9. Merhy EE. Saúde: a cartografia do trabalho vivo. São Paulo: Editora Hucitec; 2002.

10. Sá MC. Em busca de uma porta de saída: os destinos da solidariedade, da cooperação e do cuidado com a vida na porta de entrada de um hospital de emergência [Tese de Doutorado]. São Paulo: Universidade de São Paulo; 2005.

11. Campos GW, Amaral MA. Clínica ampliada e compartilhada, a gestão democrática e redes de atenção como referenciais teórico-operacionais para a reforma de hospitais. Ciênc Saúde Coletiva 2007; 12:449-59.

\section{Agradecimentos}

O trabalho contou com o financiamento do Programa Inova Ensp de Apoio à Pesquisa e Inovação para o SUS, da Escola Nacional de Saúde Pública Sergio Arouca, Fundação Oswaldo Cruz.

12. Cecílio LCO, Merhy EE. A integralidade do cuidado como eixo da gestão hospitalar. In: Pinheiro R, Mattos RA, organizadores. Construção da integralidade: cotidiano, saberes e práticas em saúde. Rio de Janeiro: Instituto de Medicina Social, Universidade do Estado do Rio de Janeiro/Abrasco; 2003. p. 199-212.

13. Campos GWS. A clínica do sujeito: por uma clínica reformulada e ampliada. In: Campos GWS, organizador. Saúde paidéia. São Paulo: Editora Hucitec; 2003. p. 51-67.

14. Azevedo CS, Sá MC. Avaliação psicossociológica de uma estratégia de humanização do tratamento do câncer infantojuvenil: o aquário carioca. In: Azevedo CS, Sá MC, organizadores. Subjetividade, gestão e cuidado em saúde: abordagens da psicossociologia. Rio de Janeiro: Editora Fiocruz; 2013. p. 359-82.

15. Enriquez E. Organização em análise. Petrópolis: Editora Vozes; 1997.

16. Enriquez E. O vínculo grupal. In: Levy A, Nicolai A, Enriquez E, Duboust J, organizadores. Psicossociologia: análise social e intervenção. Petrópolis: Editora Vozes; 1994. p. 56-79.

17. Dejours C. Trabalho e emancipação. Trabalho vivo. Tomo II. Brasília: Paralelo 15; 2012.

18. Sá MC, Azevedo CS. Subjetividade e gestão: explorando as articulações psicossociais no trabalho gerencial e no trabalho em saúde. Ciênc Saúde Coletiva 2010; 15:2345-54.

19. Gouvêa CSD, Travassos C. Indicadores de segurança do paciente para hospitais de pacientes agudos: revisão sistemática. Cad Saúde Pública 2010; 26:1061-78.

20. Quinto Neto A. Segurança dos pacientes, profissionais e organizações: um novo padrão de assistência à saúde. Rev Adm Saúde 2006; 8:153-8

21. Pereira D. Psicanálise e o transplante de medula óssea: dizer o impossível de ser dito [Dissertação de Mestrado]. Rio de Janeiro: Instituto de Psicologia, Universidade Federal do Rio de Janeiro; 2016

22. Miranda L. Criatividade e trabalho em saúde: contribuições da teoria winicottiana. In: Azevedo CS, Sá MC, organizadores. Subjetividade, gestão e cuidado em saúde. Abordagens da psicossociologia. Rio de Janeiro: Editora Fiocruz; 2013. p. 89-117. 


\section{Abstract}

The article presents partial results of a study at Hospital Edgar Santos, Universidade Federal da Bahia (HUPES), Brazil, analyzing the service's experience with improvement in quality of care within a context of hospital accreditation. The article focuses on the hematology service and specifically its quality of care and intersubjective processes. The study adopted a qualitative approach, using interviews and observation. From the theoretical point of view, the work of Campos, Cecilio, and Merhy acknowledge healthcare's complex nature and micropolitical and intersubjective dimension and the capacity of health professionals to produce meanings and practice creativity. To understand the health professionals' processes of psychosocial linkage and subjective mobilization, we drew on concepts from the French school of psychosociology (Enriquez) and Dejours' psychodynamics of work. The analysis was organized along three lines: psychosocial linkage and the imaginary of self-management; bonding and affect: singularity of the subject's care and clinical case; real work and the healthcare team. One of the main conclusions is the building of a self-management imaginary, expressed in shared projects, expectations, and some forms of interpreting and operating reality, based on affectively invested representations of autonomy and unity. Alongside technical elements such as protocols, the article highlights professional judgment, proper to the intersubjective dimension, fostering the singularity of care. In our view, the real work in the patient care scene is traversed by adjustments that demonstrate team cooperation.

Quality of Health Care; Patient Care

Management; Patient Care Team

\section{Resumen}

En este artículo presentamos parte de los resultados del estudio desarrollado en el Hospital Edgar Santos, de la Universidad Federal de Bahía (HU$P E S)$, que analizó la experiencia de mejora de la calidad de la asistencia en un contexto de acreditación hospitalaria. El artículo se dirige al servicio de hematología y centra su atención en la calidad del cuidado y procesos intersubjetivos. La investigación fue pautada desde la perspectiva cualitativa, empleando entrevistas y observación. Desde el punto de vista teórico, los trabajos de Campos, Cecílio y Merhy reconocen la naturaleza compleja del cuidado en salud, su dimensión micropolítica e intersubjetiva, y la capacidad de los profesionales para producir nuevos significados y ser creativos. Para comprender los procesos de articulación psicosocial y de movilización subjetiva de los profesionales empleamos conceptos de la psicosociología francesa de Enríquez y de la psicodinámica del trabajo de Dejours. El análisis se organizó en torno a tres ejes: articulación psicosocial e imaginario de autogestión; vínculo y afecto: singularización del cuidado y clínica del sujeto; trabajo real y equipo de salud. Destacamos como una de las principales conclusiones: la constitución de un imaginario de autogestión, traducido en compartir proyectos, expectativas y algunas formas de interpretar y manejar la realidad, que tienen como base representaciones, afectivamente invertidas, de autonomía y unidad. Junto a elementos técnicos, como los protocolos, se realza el juicio profesional, propio de la dimensión intersubjetiva, permitiendo la singularización del cuidado. Comprendemos que en la escena asistencial el trabajo real está cruzado por ajustes que demuestran la cooperación entre los profesionales.

Calidad de la Atención de Salud; Manejo de Atención al Paciente; Grupo de Atención al Paciente
Recebido em 14/Mar/2017

Versão final reapresentada em 11/Dez/2017

Aprovado em 18/Dez/2017 